\title{
Interaction between sorption and biodegradation in a biofilter packed with activated carbon
}

\author{
A. D. Dorado*, J. Lafuente**, D. Gabriel $* *$ and X. Gamisans ${ }^{\dagger}{ }^{\dagger}$ \\ *Department of Mining Engineering and Natural Resources, Universitat Politècnica de Catalunya, Bases de \\ Manresa 61-73, 08240 Manresa, Spain \\ ***Department of Chemical Engineering, Universitat Autònoma de Barcelona, Edifici C, 08193 Bellaterra, \\ Barcelona, Spain \\ † Corresponding author E-mail: xavierg@emrn.upc.edu
}

\begin{abstract}
The main objective of this study is to evaluate qualitatively and quantitatively the effect of starvation periods in the biodegradation capacity of microorganisms when the support media is a material with high sorption capacity. Pollutant sorption and biodegradation, which occur simultaneously in the biofilter, describe the overall behavior of the air treatment system during normal operation and during starvation periods. Results obtained in the present study demonstrate that sorption capacity of the material not only plays an important role during the start-up of operation, but it is also important in the steady operation. Simultaneously, as biomass grows on the support, biodegradation becomes more decisive in the performance. It was found that zones of packing material with low moisture content are controlled by the sorption mechanism, at expenses of biodegradation, and they are essential as pollutant reservoir during starvation periods. In the present study a significant decrease in the biodegradation capacity of microorganisms immobilized on activated carbon were not observed as consequence of continuously load interruptions.
\end{abstract}

Keywords: activated carbon, adsorption, biofiltration, intermittent loads.

\section{INTRODUCTION}

The nature of packing materials has proven to be a fundamental factor for the successful application of biofilters and biotrickling filters. Several packing materials have been used to treat a wide range of pollutants such as volatile organic compounds, sulfurous compounds and ammonia, among others. The election of the most suitable material is completely related to the importance of physical and chemical properties according to the main function they have to develop in a specific operation. Previous studies showed that a packing material can be suitable in a certain case operation, but hardly appropriate in others (Dorado et al. 2010a). Biofiltration packing materials comprise a relatively wide range of both organic and inorganic materials. Among their main disadvantages, organic materials tend to be eventually biodegraded bringing a loss of structure as well as require of frequent replacement. Inorganic materials have uniform structure and size which reduce compaction and allow better air distribution, resistance to water addition and can be cleaned and regenerated (Ortiz et al. 2003).

In the case of industrial emissions, where intermittent loads are usually presented, the sorption capacity of the support media can be an interesting characteristic to consider in the election of the most suitable packing material. In fact, fluctuations in pollutant inlet concentrations adversely influence the effectiveness of bioreactors for waste gas treatment. It is believed that biomass starvation adversely affects biological activity, especially in long-term starvation conditions, but few studies have focused on the effect of intermittent loads on microorganisms' activity. It has been hypothesized that in repetitive cycles of load interruption, activity of microorganisms could be significantly reduced affecting the biodegradation capacity to abate pollutants in the biofilter, causing a negative impact in the stability of long term operations. The application of an adsorbent to buffer the negative effect of such fluctuations improves the overall process. High pollutant concentrations can be toxic for the microorganisms immobilized in the reactor, causing the inactivation of the system. A rapid desorption may keep the microorganisms healthy and sustain 
high degradation rates even when concentrations are falling, besides reducing stress on the microbial population when concentrations rise (Moe \& Li 2005).

It has been already demonstrated that high sorption capacities of some packing material can be strongly affected by the presence of water under the normal operating conditions of a biofilter (Dorado et al. 2010b). The water film on materials creates a high resistance to mass transfer, especially in the case of hydrophobic compounds. Therefore, pollutant concentrations on the liquidsolid interface of wet materials are lower than the concentrations on the gas-solid interface in dry conditions. As liquid-phase diffusion is much slower than gas-phase diffusion, the pollutant is hardly adsorbed over short contact times. Moreover, previous works have reported that water competes for adsorptive sites when a biofilter is put into operation (Loy et al. 1997). In a previous study of Dorado et al. (2010b) a commercial activated carbon (CAC) retained in its structure 500 times the amount of pollutant retained in classic packing materials even though the sorption capacities of tested materials decrease an average of $60 \%$ with respect to dry conditions.

The effectiveness of activated carbon as packing material in biofiltration has been successfully reported in several works. Abumaizar et al. (1998) showed that biofilters containing granular activated carbon exhibited significantly higher removal efficiencies and more stable operation during sudden load increases than biofilters containing only compost. Ortiz et al. (2003) studied the effect of the presence of activated carbon in a vermiculite-based biofilter observing positive effects in the removal efficiencies. Dorado et al. (2009) demonstrated that a sludge-based carbon with a high capacity to smooth inlet load changes was a good support to immobilize and grow the biomass obtaining relative good removal efficiencies (up to 90\%). Li et al. (2002) showed that activated carbon was capable of efficiently biodegrading gas mixed with toluene and benzene in a biofilter with EC values of 150 and $120 \mathrm{~g} \mathrm{~m}^{-3} \mathrm{~h}^{-1}$, respectively. Similar results have been observed for other compounds. Duan et al. (2007) studied the simultaneous effect of biodegradation and sorption of hydrogen sulfide on the surface of activated carbon and concluded that the biofilm developed on carbon surface improves the removal of $\mathrm{H}_{2} \mathrm{~S}$ in comparison to an abiotic system. On the contrary, Aizpuru et al. (2003) achieved a removal efficiency of $90 \%$ in a peat biofilter and an $80 \%$ in a granular activated carbon for abatement of VOCs. It was assumed that the sorptive properties of activated carbon could modify the degradation mechanism and then implicate a real reduction of the removal efficiency. Likewise, Kwon \& Cho (2009) observed better performance in a biofilter with packed cork than one with activated carbon. After 4 months of operation, higher biomass in the cork was counted even if the specific surface area of activated carbon was 12 times larger.

Dampening the fluctuating concentrations has been a recent research objective in order to enhance the reliability of biofilters to promote their application at real scale (Alvarez-Hornos et al. 2008; Sempere et al. 2009). Most of studies using activated carbon as packing material focused on placing a separate carbon column before the biofilter, preventing the presence of water to ensure a stable pollutant concentration to degrade in a posterior biofilter (Weber \& Hartmans 1995). However, little is known about the use of the adsorptive material as the support media, which results in important savings in ancillary equipment and space. Previous studies only point out that packing materials with high sorption capacity are decisive to avoid pollutant concentration at the biofilter outlet during the start-up, but nothing is commented about the influence of sorption capacity in the behavior of the biofilter while biomass is growing after the start-up.

The aim of this work is to evaluate qualitatively and quantitatively the effect of starvation periods in the activity of microorganisms for the abatement of a common VOC (toluene) when the support media is a material with high sorption capacity (activated carbon). The primary objective is to detail how the simultaneous mechanisms occurring in this case, sorption and biodegradation, could be affected by each other before, during and after episodes of intermittent loads. Several parameters 
were monitored in the evolution of the biofilter from the inoculation to several forced starvation periods in five sampling ports along the height of the biofilter to determine the corresponding profiles during the several periods of operation.

\section{MATERIALS AND METHODS}

\section{Experimental setup}

Experiments were carried out in a lab-scale plant consisting of a PVC column with an inner diameter of $14.5 \mathrm{~cm}$ and a packing height of $1 \mathrm{~m}$ (Figure 1) with a total packing volume of $16.5 \mathrm{~L}$ and a bed porosity of 0.31 . Five sampling ports located along the height of the biofilter let to describe concentration profiles from the inlet (port A) to the outlet (port E). Therefore, the biofilter was split in 4 modules of the same size. Compressed air was passed through a water column in order to increase the relative humidity. Water was sprinkled by a high-performance hollow cone nozzle (Bete WL1) located at the top of the fixed bed and by means of a peristaltic pump (Magdos LT-10) in down-flow mode. The inlet pollutant concentration was achieved dispensing toluene (Panreac 99.5\%, Spain) by means of an automatic microburette (Crison 2S-D, Spain). The reactor was inoculated with activated sludge from an urban wastewater treatment plant.

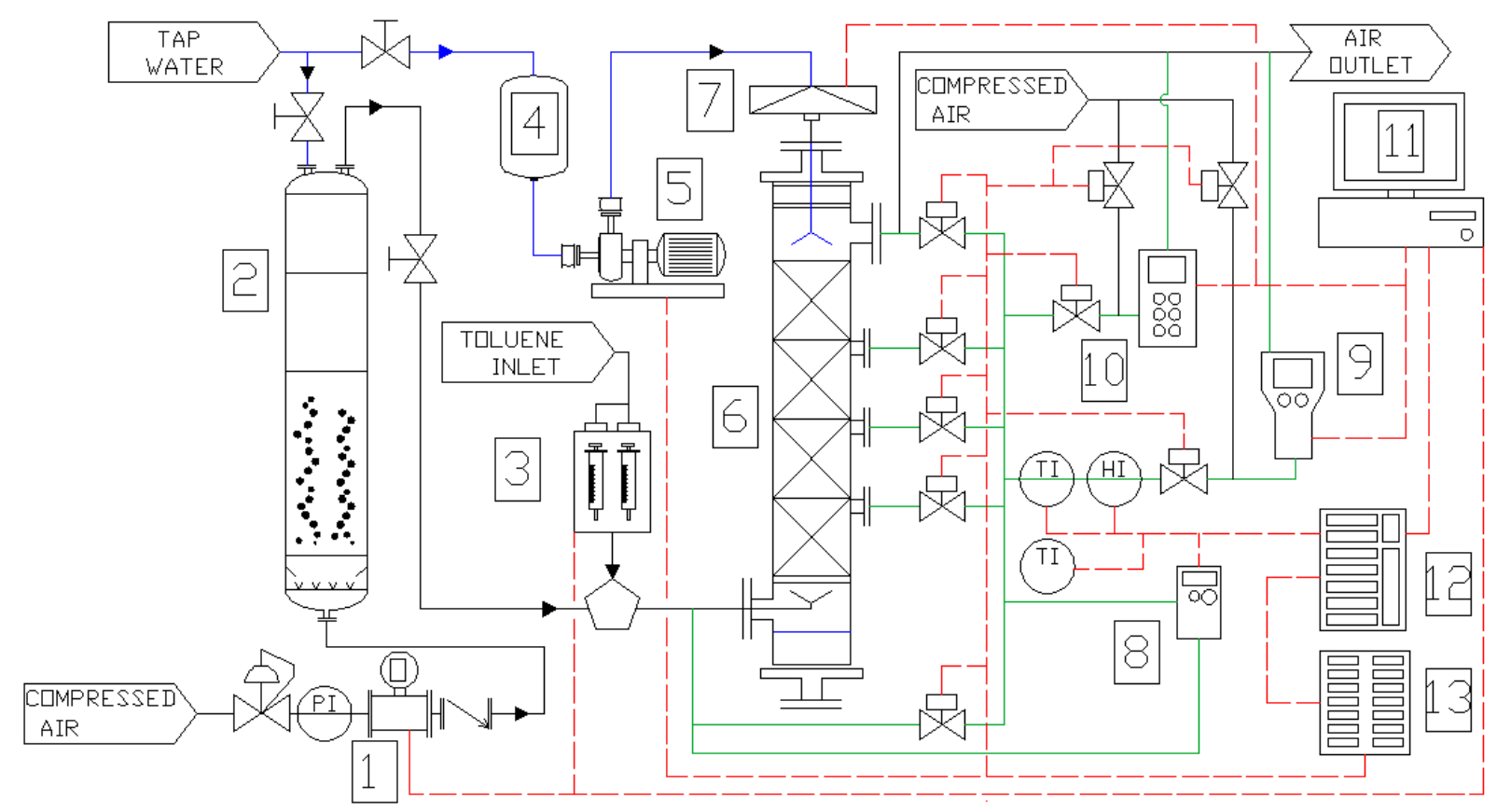

Figure 1. Schematic of the lab scale plant: 1: mass flow meter; 2: humidification column; 3: microburette; 4: nutrients tank; 5: peristaltic pump; 6: biofilter; 7: scales; 8: differential pressure meter; 9: VOC's detector; 10: $\mathrm{CO} 2 / \mathrm{O} 2$ analyser; 11: computer; 12: data acquisition hardware; 13: relays

Parameters related with biofilter performance were monitored through 5 sampling ports along the height of the biofilter to obtain profiles during operation. Sampling ports were tagged A, B, C, D and $\mathrm{E}$, from biofilter inlet to outlet separated by a distance of $25 \mathrm{~cm}$. The biofilter performance was evaluated in terms of elimination capacity $(\mathrm{EC})\left(\mathrm{g}\right.$ toluene $\cdot \mathrm{m}^{-3}$ reactor $\left.\cdot \mathrm{h}^{-1}\right)$.

A set of solenoid valves allowed on-line monitoring of toluene concentration, carbon dioxide, oxygen consumption, differential pressure, weight and temperature. A structured control system with a Supervisory Control and Data Acquisition (SCADA) software were used to automate the pilot plant and for data acquisition. The system was also used for regulating the water addition (700 mL each 12 hours) in order to keep suitable moisture content, provide the necessary nutrients for the microorganisms and wash out dead cells and end-products of toluene degradation. Nutrient 
solution was automatically sprinkled daily over the biofilter bed by means of a diaphragm dosing pump (Alldoss, Primus 221).

\section{Operational conditions}

Gas flow rate was adjusted at $28 \mathrm{~L} \mathrm{~min}^{-1}$ (empty bed residence time of 35 seconds). Inlet toluene concentration was increased progressively in the startup of the plant and kept to approximately 700 ppm in the steady operation. This high pollutant concentration is not common in most industrial facilities (it could be found in emissions from paint factories), but it was chosen to intensify biological and physical-chemical effects in the performance of the biofilter. Deliberated shutdowns of 2.5 days were caused, once the steady operation was reached, to simulate a plant shutdown during weekends. The nutrient solution was composed by $\mathrm{KH}_{2} \mathrm{PO}_{4}\left(1 \mathrm{~g} \mathrm{~L}^{-1}\right), \mathrm{K}_{2} \mathrm{HPO}_{4}\left(1 \mathrm{~g} \mathrm{~L}^{-1}\right)$, $\mathrm{NH}_{4} \mathrm{Cl}\left(1 \mathrm{~g} \mathrm{~L}^{-1}\right), \mathrm{NaCl}\left(1 \mathrm{~g} \mathrm{~L}^{-1}\right), \mathrm{MgSO}_{4}\left(0.2 \mathrm{~g} \mathrm{~L}^{-1}\right), \mathrm{CaCl}_{2}\left(0.02 \mathrm{~g} \mathrm{~L}^{-1}\right)$ and trace elements $\left(1 \mathrm{~mL} \mathrm{~L}^{-}\right.$ $\left.{ }^{1}\right)$.

\section{Packing material}

The biofilter was packed with commercial activated carbon provided by Chemviron (United Kingdom) with a total weight of $12 \mathrm{~kg}$. The material is pelletized to cylindrical particles of $3 \mathrm{~mm}$ diameter (AP3-60). Specific surface area of the material was $950 \mathrm{~m}^{2} \mathrm{~g}^{-1}$ and the bulk density was $520 \mathrm{Kg} \mathrm{m}^{-3}$. Sorption capacity of the material was calculated in a previous study in dry and wet conditions obtaining maximum values of 244 and $223 \mathrm{mg} \mathrm{g}^{-1}$, respectively (Dorado et al. 2010b). Physico-chemical characteristics of the packing material were determined for the packing material (data can be found elsewhere, (Dorado et al. 2010a)).

\section{Analytical methods}

Toluene concentration in air was measured in the sampling ports by an on-line photo ionization detector with an accuracy of $1 \%$ (Photovac 2020). The detector was connected to a computer via a RS232 port for continuous data collection. Carbon dioxide and oxygen concentrations were measured with a gas analyzer (Maihak S710) by infrared (IR) with a NDIR UNOR module for $\mathrm{CO}_{2}$ measurements and by paramagnetism with an OXOR-P module for $\mathrm{O}_{2}$ measurements. Pressure drop was determined by means of a differential pressure transmitter (Testo 6342) which provided 4-20 mA output signal. Temperature was measured by an industrial transmitter (Hygrotest $650 \mathrm{HP}$ ). Gasphase parameters were obtained for each module separately by means of a programmed sequence for the solenoid valves.

The excess of solution (leachate) was manually collected on a daily basis at the bottom section. Leacheate $\mathrm{pH}$ (Crison) and TSS by standard methods were determined while anionic species content (mainly $\mathrm{Cl}^{-}, \mathrm{SO}_{4}{ }^{-2}, \mathrm{NO}^{-3}$ and $\mathrm{PO}_{4}{ }^{-3}$ ) were determined by ionic chromatography (dionex ICS1000). Anion concentrations in the leachate collected indicated that biofilter was not limited by nutrients during the whole operation period (data not shown).

\section{RESULTS AND DISCUSSION}

\section{Pollutant removal in intermittent biofilter operation}

The performance of the biofilter was evaluated in terms of elimination capacity (EC) and removal efficiency (RE) from the inlet (port A) to the outlet (port E).

Biofilter performance was monitored for one month and a half. Once the steady operation of the biofilter was achieved, 3 shutdowns were practiced at different operation periods. The first 
shutdown was forced between days 25 and 27, the second one between days 32 and 34 and the latter between days 39 and 41 . Time span was selected to simulate a feed stop during a weekend in an industrial facility to observe its effect on the ability of the microorganism to degrade pollutants during the starvation period and after feeding resumption (Figure $2 \mathrm{a}$ ).

During the startup, the inlet load was increased progressively. During the first days a complete elimination capacity was found. It is further known that the high sorption capacity of the activated carbon plays an important role during the startup of the operation of a biofilter. Hodge \& Devinny (1995) noted that adsorption was the controlling mechanism of pollutant removal during startup. Abumaizar et al. (1998) observed the same effect for the initial spike increase in inlet concentration of BTEX in a compost/granular activated carbon biofilter.

Analyzing the elimination capacities achieved by each module (Figure 2b), the amount of pollutant abated in the first module (up to $1160 \mathrm{~g} \mathrm{~m}^{-3} \mathrm{~h}^{-1}$ ) was always superior to the rest (an average of $300 \mathrm{~g}$ $\mathrm{m}^{-3} \mathrm{~h}^{-1}$ ), except for punctual episodes. However, the dynamics of each module must be analyzed to clarify if the pollutant is removed by adsorption or biodegradation. Thus, after sudden changes in feeding, concentrations measured in port B were satisfactory smoothed unlike the rest of the biofilter; being this a first indication that the module closer to the inlet port is mainly controlled by sorption. A prior characterization of the sorption capacity of the material, evaluated by frontal analysis following the staircase method, determined that the activated carbon was completely saturated in 11 days for this inlet pollutant load when it was completely covered by water.

Once the inlet load was stopped for 2 days, measured concentrations along the height of the biofilter decreased progressively. At the inlet load treated in this system (around $500 \mathrm{~g} \mathrm{~m}^{-3} \mathrm{~h}^{-1}$ ), this period of time is not long enough to completely desorb the amount of pollutant retained in the previous period (before the stop feeding). Consequently, microorganisms immobilized on the material are not starved although the inlet load of the biofilter is interrupted. This situation favored the rapid recovery of the elimination capacity when the effluent to treat was doped again. As shown before, the inlet concentration to the second module (concentration B) exhibited a delayed profile with regard to the increase in the concentration at the biofilter inlet (concentration A). Therefore, the pollutant load in the second module was smoothed by the sorption capacity of the former (clearly visible after the second stop feeding, after day 34). 


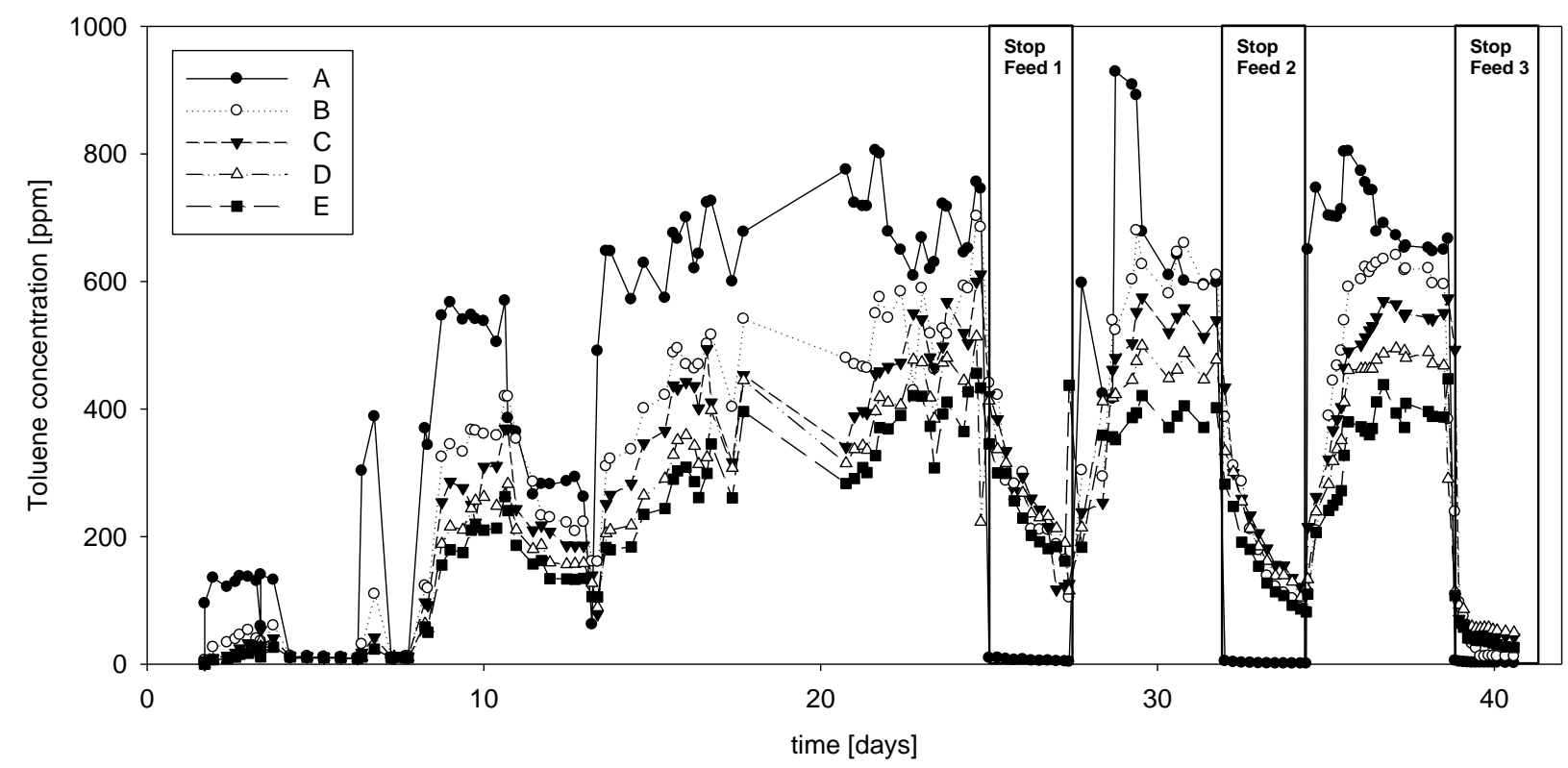

Figure 2a. Evolution of toluene concentration at different heights of the biofilter (A at the inlet, $\mathrm{B}, \mathrm{C}$ and $\mathrm{D}$ at the subsequent upper levels and $\mathrm{E}$ at the outlet).

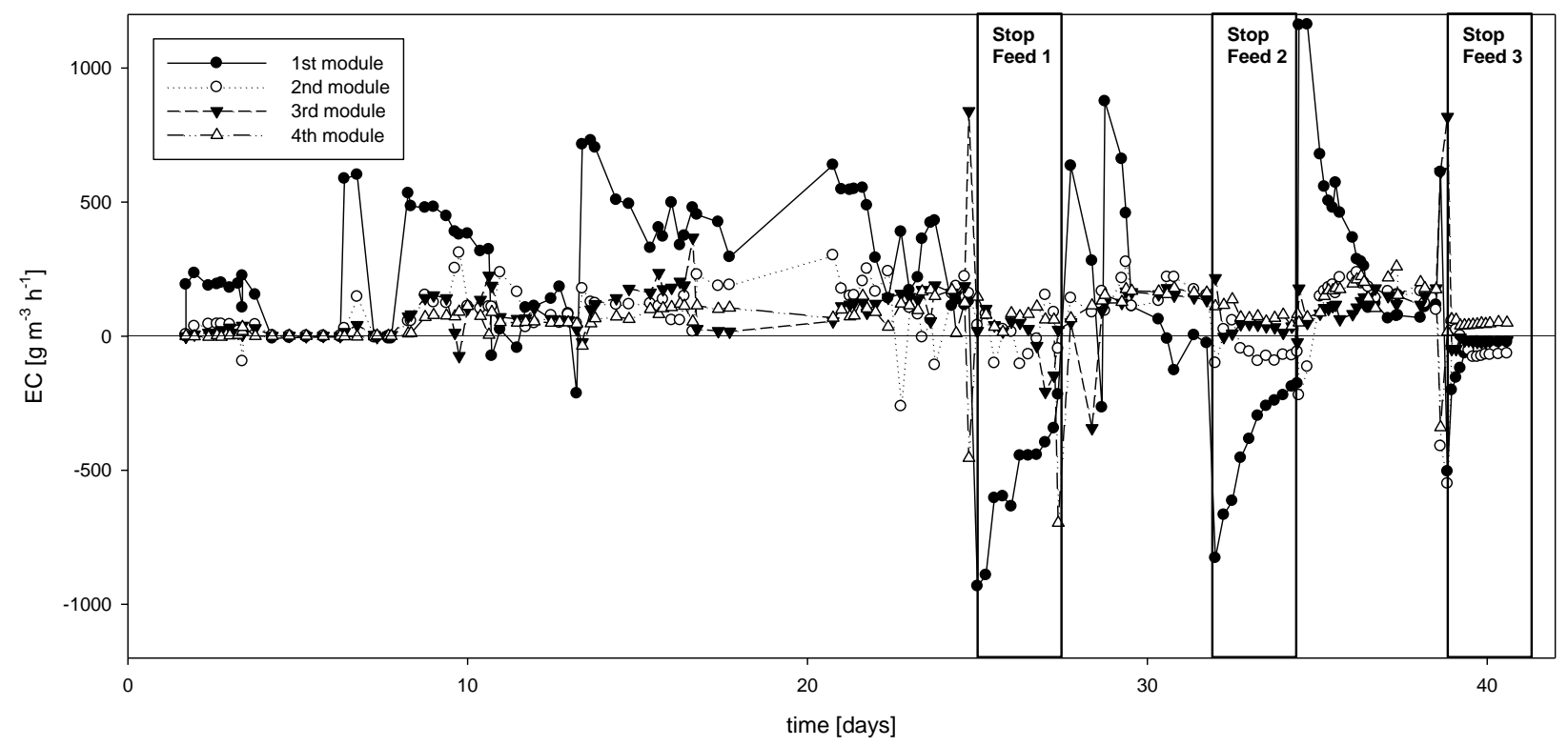

Figure 2b. Evolution of elimination capacities at different modules of the biofilter from the inlet (first module) until the outlet (fourth module).

Comparing the third stop feeding with others, toluene concentration detected was significantly lower than previously (Figure2a). This might indicate that sorption process is negatively affected by the expansion of biomass in thickness and surface covering. This was corroborated by pressure drop values measured (Figure 3a) along the different ports of the biofilter which means that biomass is slightly increasing along the operation period. However, observing only the toluene profiles or the elimination capacities achieved in each module is not conclusive whether the pollutant was abated 
by the sorption capacity of the packing material or by the action of microorganisms immobilized on this material. To better distinguish which mechanism controlled the process, the analysis of the evolution of carbon dioxide production was also performed (Figure $3 b$ ).

\section{Carbon dioxide production in intermittent biofilter operation}

Carbon dioxide production is a direct indicator of the microorganisms' activity on the support media. The carbon dioxide produced may be accumulated in the aqueous phase and biofilm as one of its aqueous species, $\left(\mathrm{HCO}_{3}{ }^{-}, \mathrm{H}_{2} \mathrm{CO}_{3}\right.$ or $\left.\mathrm{CO}_{3}{ }^{2-}\right)$. However, in the present study significant changes in carbon dioxide production after each intermittent watering were not detected, indicating that carbon dioxide stripping was not determinant. Therefore, carbon dioxide monitoring is perfectly correlated with biodegradation capacity of microorganisms without remarkable interferences.

Figure $3 b$ shows the carbon dioxide production plotted along the time operation. It is noteworthy that the several stop feeding did not affect significantly the amount of carbon dioxide produced. Relating this observation with toluene profiles described in the starvation periods, it could be concluded that the amount of toluene desadorbed during these periods and a possible fraction of inactive biomass used as carbon source are enough to keep active the biomass immobilized on the material. In fact, after the first stop feeding, the production of carbon dioxide is increased once the inlet load is restored; indicating that biomass was not limited by biodegradation at these conditions.

Results show that carbon dioxide production was enhanced at upper modules of the biofilter. The production of carbon dioxide in the first module is around $250 \mathrm{~g} \mathrm{~m}^{-3} \mathrm{~h}^{-1}$, which is considerably lower than in any other modules. Biomass immobilized in the second module produce an average of carbon dioxide of $850 \mathrm{~g} \mathrm{~m}^{-3} \mathrm{~h}^{-1}$ while the second and the third module produce $1100 \mathrm{~g} \mathrm{~m}^{-3} \mathrm{~h}^{-1}$ and $1500 \mathrm{~g} \mathrm{~m}^{-3} \mathrm{~h}^{-1}$ respectively. Carbon dioxide profiles monitored show that even though the first module is the zone where the elimination capacity is enhanced, this module is not the area where microorganisms oxidize the highest amount of toluene. This observation is clear evidence that the first module is controlled mainly by sorption processes. In this same way, during desorption periods, toluene concentrations measured in the different ports are similar, as exception of the outlet of the first module where the amount of toluene desorbed is higher. Therefore, the first module acts as a reservoir of pollutant for the rest of the biofilter when shutdowns occur. This observation indicates that the same effect of using a previous activated carbon bed to dampen intermittent loads can be achieved in the same biofilter, saving equipment and space. 


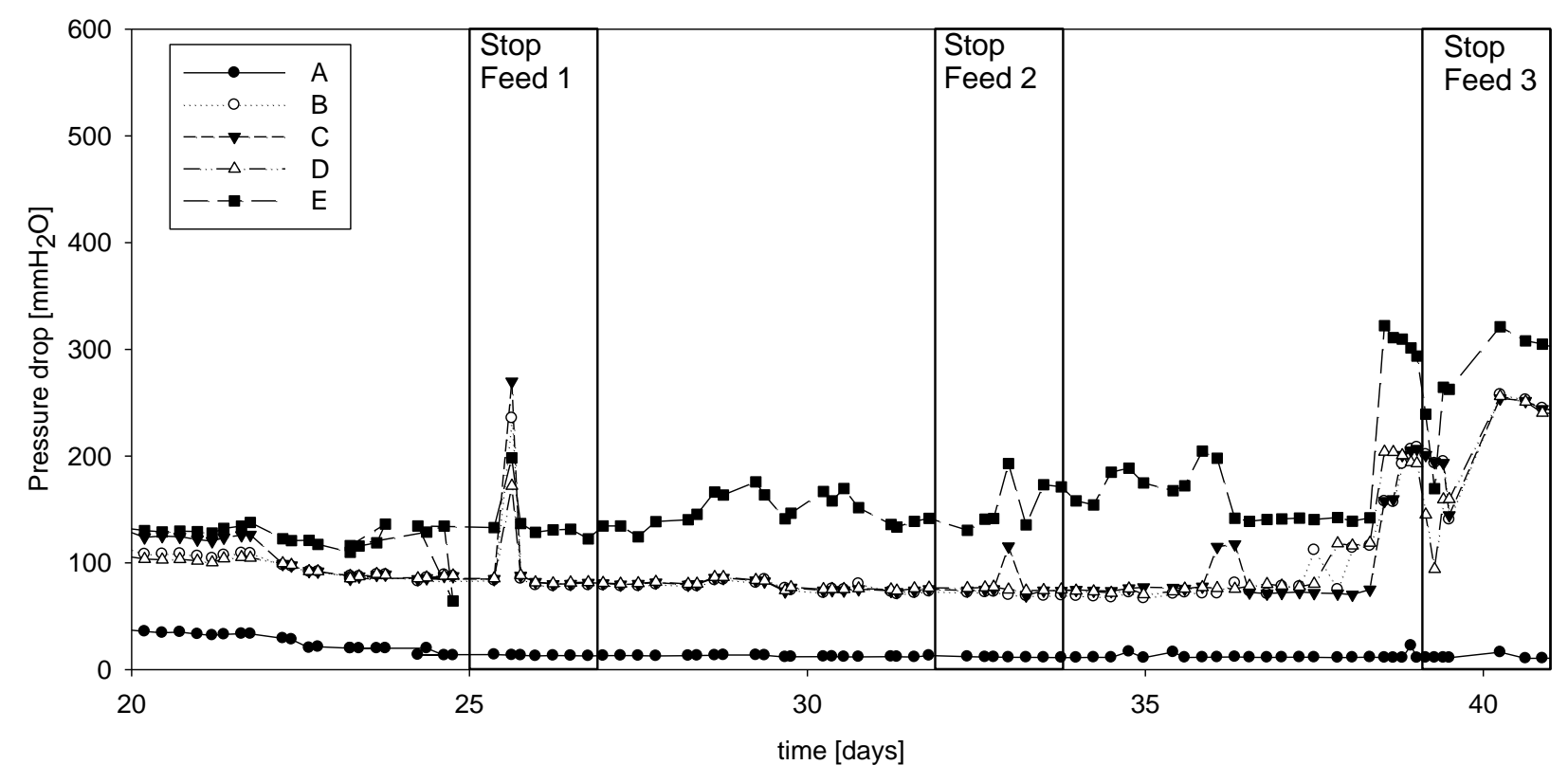

Figure 3a. Evolution of pressure at different heights of the biofilter (A at the inlet, B,C and D at the subsequent upper levels and $\mathrm{E}$ at the outlet).

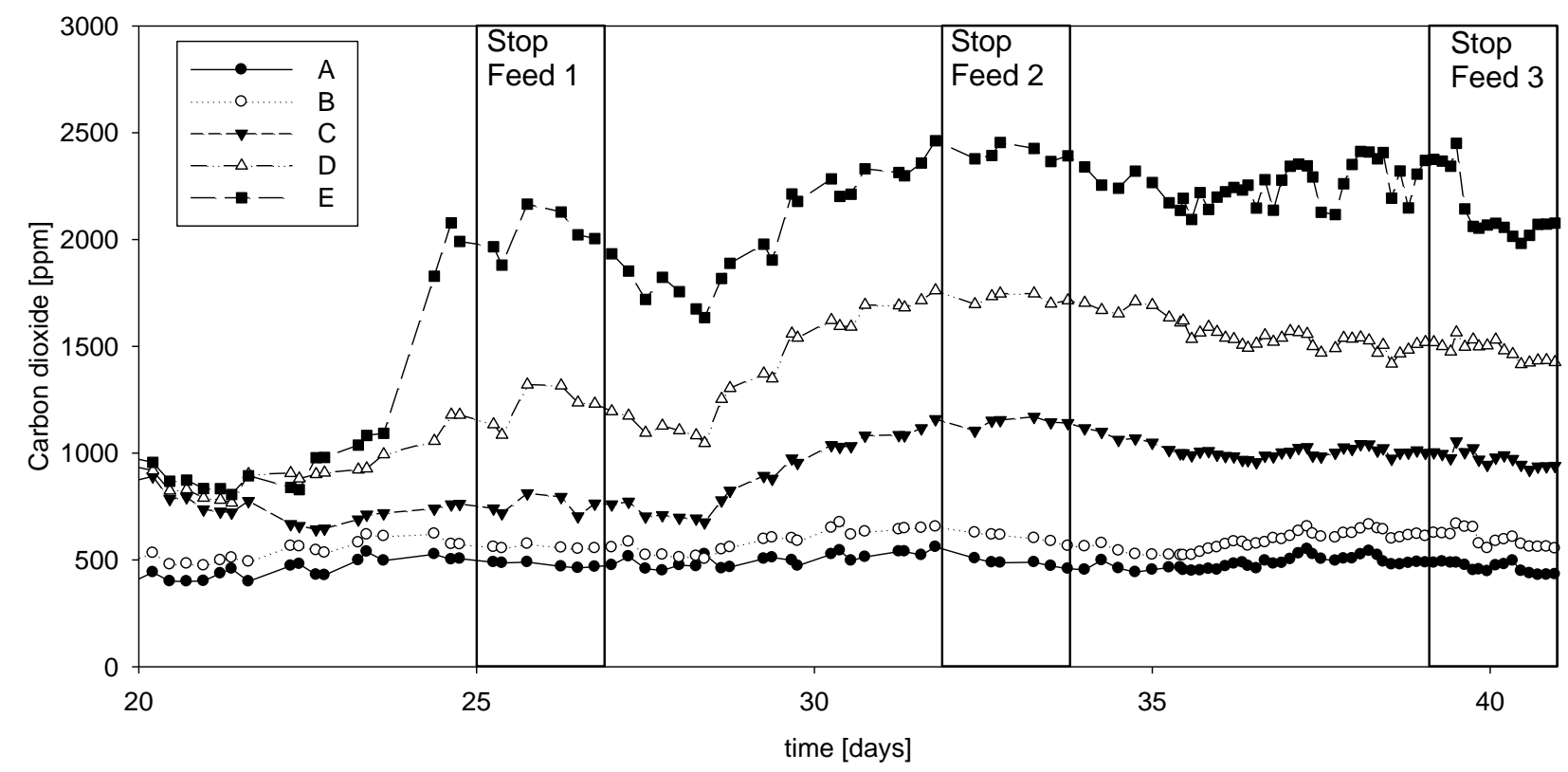

Figure 3b. Evolution of carbon dioxide concentration at different heights of the biofilter (A at the inlet, B,C and D at the subsequent upper levels and E at the outlet).

\section{Sorption and biodegradation processes interaction}

Carbon dioxide and toluene profiles are not completely correlated in all the zones of the biofilter. The fact that the first module is controlled by the sorption mechanisms is closely related with the water content of the packing material in this area of the biofilter. Periodical measurements indicate that moisture content in areas close to the inlet is significantly lower than in upper levels (from 21 to $39 \%$ ). Since irrigation is realized from the top of the biofilter, in countercurrent to gas inlet, the zone with the highest moisture content is the upper of the bed. Besides, water loss in biofilters has 
been reported to be hastened by metabolic heat due to high EC. On the one hand, the lack of moisture negatively affects the maintenance and development of microorganism immobilized on the packing material of the first module, i.e. pollutant biodegradation is injured close to the inlet. On the other hand, it has been demonstrated that the presence of water in a bed weakens the interaction bond between contaminant and the surface of the material (Dorado et al. 2010b). Indeed, the necessity of water in a biofilter is one of the most important parameters for avoiding poor system operation, despite adsorption capacity of those materials covered with water during a biofilter normal operation is considerably depleted, especially for hydrophobic pollutants such as toluene. This would explain the favored pollutant sorption close to the inlet in the present study.

Pressure drop monitored along the biofilter denotes that the maximum resistance to the gas flow is concentrated in the last module. The increase in pressure drop is related with biomass growth but it is also a direct consequence of water accumulation in this zone. These results are in concordance with the high biodegradation activity registered in the top of the biofilter, according to measured carbon dioxide production. Although starvation is used as a technique to wash out the excess of biomass inside a biofilter in some cases (Delhomenie et al. 2003), in the present study pressure drop did not decrease during the lack of feeding.

During feeding stops, the upper biofilter modules continued removing pollutant (Figure 2b), in this case, toluene from desorption of the first module. Therefore, biomass continued developing although the bioreactor was not fed, meaning that the upper packing material retains that pollutant delivered from the lower layers, saturating the support. Previous studies have observed that pollutant desorption from a granular activated carbon served as an extra source of substrate to a biotrickling filter (Sempere et al. 2009). In the present case, although the elimination capacities are practically constant (around $300 \mathrm{~g} \mathrm{~m}^{-3} \mathrm{~h}^{-1}$ ) before and after each feeding stop, the amount of carbon dioxide produced is enhanced after each stopping, indicating that the fraction of pollutant biodegraded is higher during the operation at expenses of pollutant adsorbed. If elimination capacities remain constant, the increase in carbon dioxide concentration can be only attributed to the microorganisms, which are also able to oxidize the organic matter previously adsorbed on the surface of the material. In this sense, Ortiz et al. (2003) affirmed that sorption can favor the contact between microorganisms and the pollutants.

As shown in Figure 3b, the maximum overall elimination capacity was obtained immediately after each stop feeding (1160 $\left.\mathrm{g} \mathrm{m}^{-3} \mathrm{~h}^{-1}\right)$, where the sum of effects (adsorption and biodegradation) are underlined. Once the material was saturated, the mechanism that controls the process was the biodegradation capacity of the biomass, obtaining higher elimination capacities in the second module firstly, and in the third and forth later on. The first module, where the biomass has not been developed, worsens the effectiveness of the process once the material is saturated. However, the presence of a prior zone working as pollutant buffer let to keep the biological process during the whole operation independently of the intermittence of loads. The action of both mechanisms working simultaneously, not only avoids subjecting biomass under stress, but also let to ensure high elimination capacities by the sum of effects for biofilter operating when intermittent loads are present.

Regarding $\mathrm{pH}$ measurements in leachate (results not shown), chemical composition of aqueous phase was not affected by the different feeding interruptions. The $\mathrm{pH}$ measured decreased slightly from the initial value of 8 until a value of 6 after 40 days of operation. In previous studies, Maestre et al. (2007) modeled a biofilter treating toluene packed with coconut fiber and pine leaves where after 50 days of operation the $\mathrm{pH}$ dropped at values as low as 3 . It was considered that the decrease in $\mathrm{pH}$ was in relation to the production of acidic by-products such as benzoic acid, which arise from 
toluene degradation. In the present study it is suggested that sorption capacity of the support can be useful to decrease medium acidification and the likely changes in population which are associated.

\section{CONCLUSIONS}

The effect of starvation periods in the activity of microorganisms for the abatement of toluene when the support media is activated carbon has been evaluated qualitatively and quantitatively. The simultaneous mechanisms occurring in the biofilter, pollutant sorption on the surface of the material and degradation by the microorganisms immobilized on the support, and their interactions, describe the overall behavior of the air treatment system when intermittent loads are present. Firstly, high sorption capacity of the activated carbon plays an important role during the startup of the operation of the biofilter. However, once the biomass is developed on the surface of the material, two different areas are detected. First zone where sorption capacity of the material is the mechanism controlling the abatement of pollutant and second zone where biodegradation is the critical factor for the successful of the operation.

In the present study the area closest to the inlet is controlled by the sorption mechanism which is strictly related with the moisture content of the packing material. Since irrigation is realized from the top of the biofilter, in countercurrent to the gas inlet, the zone with the highest moisture content is the upper of the bed. The lack of moisture negatively affects the maintenance and development of microorganism immobilized on the packing material. On the contrary, zones with high water content weaken the interaction bond between contaminant and the surface of the material and the high sorption of the activated carbon is seriously injured. As biomass growth is occurring, sorption capacity of the material is depleted at expenses of an increase in the biological oxidation of the pollutant, i.e. microorganisms' activity.

Coexistence of both mechanisms in the biofilter contributes to an optimal operation for the treatment of hydrophobic pollutants, especially in the case of intermittent loads which can be frequent in real industrial facilities. Drier zones, with higher sorption capacities, act as a pollutant reservoir decreasing stress on microbial population during starvation periods when an extra carbon source is needed without the necessity of an activated carbon pre-filter, being a more economical alternative. Present results show that microorganisms are also able to oxidize the organic matter previously adsorbed on the surface of activated carbon during starvation periods and also during the steady operation.

\section{ACKNOWLEDGEMENTS}

This work was supported by the Spanish Comisión Interministerial de Ciencia y Tecnologia (CICYT) project CTM2009-14338-C03-03.

\section{References}

Abumaizar R. J., Kocher W. and Smith E. H. (1998). Biofiltration of BTEX contaminated air streams using compost-activated carbon filter media. J Hazard Mater. 60(2), 111-126.

Aizpuru A., Malhautier L., Roux J. C. and Fanlo J. L. (2003). Biofiltration of a mixture of volatile organic compounds on granular activated carbon. Biotechnol Bioeng. 83(4), 479-488.

Alvarez-Hornos F. J., Gabaldon C., Martinez-Soria V., Marzal P. and Penya-roja J. (2008). Biofiltration of toluene in the absence and the presence of ethyl acetate under continuous and intermittent loading. J Chem Technol Biotechnol. 83(5), 643-653. 
Delhomenie M. C., Bibeau L., Gendron J., Brzezinski R. and Heitz M. (2003). A study of clogging in a biofilter treating toluene vapors. Chem Eng J. 94(3), 211-222.

Dorado A. D., Lafuente F. J., Gabriel D. and Gamisans X. (2010a). A comparative study based on physical characteristics of suitable packing materials in biofiltration. Environ Technol. 31(2), 193-204.

Dorado A. D., Hernandez J., Ribera G., Gabriel D., Lafuente J. and Gamisans X. (2009). Evaluation of sludge-based carbon as packing material in biofiltration in comparison to classic materials. Water Practice \& Technology. 4(2), 1-4.

Dorado A. D., Lafuente J., Gabriel D. and Gamisans X. (2010b). The role of water in the performance of biofilters: Parameterization of pressure drop and sorption capacities for common packing materials. J Hazard Mater. 180(1-3), 693-702.

Duan H., Yan, R., Koe, L.C.C., Wang, X. (2007). Combined effect of adsorption and biodegradation of biological activated carbon on $\mathrm{H} 2 \mathrm{~S}$ biotrickling filtration. Chemosphere 66 , 1684-1691.

Hodge D. S., Devinny J. S. (1995). Modeling Removal of Air Contaminants by Biofiltration. $J$ Environ Eng -ASCE. 121(1), 21-32.

Kwon S., Cho D. (2009). A comparative, kinetic study on cork and activated carbon biofilters for VOC degradation. J Ind Eng Chem. 15(1), 129-135.

Li G. W., Hu H. Y., Hao J. M. and Zhang H. Q. (2002). Biological treatment characteristics of benzene and toluene in a biofilter packed with cylindrical activated carbon. Water Sci Technol. 46(11-12), 51-56.

Loy J., Heinrich K. and Egerer B. (1997). Influence of filter material on the elimination rate in a biotrickling filter bed. Air \& Waste.

Maestre J. P., Gamisans X., Gabriel D. and Lafuente J. (2007). Fungal biofilters for toluene biofiltration: evaluation of the performance with four packing materials under different operating conditions. Chemosphere. 67, 684-692.

Moe W. M., Li C. N. (2005). A design methodology for activated carbon load equalization systems applied to biofilters treating intermittent toluene loading. Chem Eng J. 113(2-3), 175-185.

Ortiz I., Revah S. and Auria R. (2003). Effects of packing material on the biofiltration of benzene, toluene and xylene vapours. Environ Technol. 24(3), 265-275.

Sempere F., Gabaldon C., Martinez-Soria V., Manuel Penya-Roja J. and Javier Alvarez-Hornos F. (2009). Evaluation of a combined activated carbon prefilter and biotrickling filter system treating variable ethanol and ethyl acetate gaseous emissions. Eng Life Sci. 9(4), 317-323.

Weber F. J., Hartmans S. (1995). Use of Activated Carbon as a Buffer in Biofiltration of Waste Gases with Fluctuating Concentrations of Toluene. Appl Microbiol Biotechnol. 43(2), 365-369. 